\title{
Studies on Riboflavin Tetranicotinate
}

\section{Some Physiological and Pharmacological Tests}

\author{
Akira Kotaki, Keilchi Kato, Misao OKumura, \\ Torao SAKUrai and Kunio Yagi ${ }^{2}$
}

\author{
Institute of Biochemistry, Faculty of Medicine, \\ University of Nagoya, Showa-ku, Nagoya
}

(Received February 14, 1968)

1. Riboflavin $2^{\prime}, 3^{\prime}, 4^{\prime}, 5^{\prime}$-tetranicotinate $\left(\mathrm{B}_{2}-\mathrm{Nic}\right)$ showed vitamin effect on rat, although its effect was somewhat lower than that of free riboflavin (FR). This compound was also found to be somewhat inferior to FR for the maintenance of the hepatic and the renal flavin levels. However, by increasing the dose of its administration, flavin levels of these organs can be elevated.

2. The rate of excretion of flavin into urine of animals administered with $\mathrm{B}_{2}-\mathrm{Nic}$ was found to be considerably lower than that of animals administered with $F R$, suggesting that $B_{2}-N i c$ was more accumulative in living body than FR. Moreover, it was found that $\mathrm{B}_{2}-\mathrm{Nic}$ was superior to $\mathrm{FR}$ in keeping blood flavin level higher than the normal for a long time. It is, therefore, suggested that this compound could be beneficially used as deposit-type riboflavin.

3 . In acute toxicity test of $\mathrm{B}_{2}-\mathrm{Nic}$, mice and rats were administered orally with $1.0 \mathrm{~g} / \mathrm{kg}$ body weight and $5.0 \mathrm{~g} / \mathrm{kg}$ body weight of this compound, respectively, but no death was found after 72 hours of administration. No difference was found in appearance and in appetite, between animals tested and those of control. In chronic toxicity test, rats were administered compulsorily with $230 \mathrm{mg} / \mathrm{day} / \mathrm{kg}$ body weight of this compound. The body weight gains of the rats tested were the same with those of control rats. After 6 months' feeding, the measurement of the weight of each organ, hematological examination on blood, and histological investigation of organs and tissues were made. No difference was found between the rats fed on $\mathrm{B}_{2}-\mathrm{Nic}$ and those of control, indicating that this compound has no chronic toxicity up to the dose of $230 \mathrm{mg} / \mathrm{day} / \mathrm{kg}$.

\footnotetext{
${ }^{1}$ Following abbreviations were used: FR, free riboflavin; $\mathrm{B}_{2}$-Nic, riboflavin $2^{\prime}, 3^{\prime}, 4^{\prime}, 5^{\prime}-$ tetranicotinate.

2 小滝 祥, 加藤慶一, 奥村ミサヨ, 桜井寅雄, 八木国夫.
} 
Considering that riboflavin and nicotinic acid can be altered to their so-called "deposit-type" by esterifying the former with fatty acids (1) and the latter with alcohols (2), and that riboflavin tetrabutyrate (3) and myoinositol hexanicotinate (4) are the respective examples, we have had an idea that both riboflavin and nicotinic acid may be altered to their deposit-type by merely esterifying the former with the latter. To bring this idea into practice, $\mathrm{B}_{2}-\mathrm{Nic}$ has been synthesized in our laboratory (5). As was expected, this newly synthesized riboflavin derivative was found to possess a lipotropic nature differing from FR. However, its solubility is of a medium nature between FR and riboflavin tetrabutyrate; it was found to be soluble in water as well as in triglycerides.

Therefore, it may be possible to consider that this riboflavin derivative would be valuable in developing the usefulness of not only riboflavin, but also nicotinic acid, if it possesses similar or even some additional medical and nutritional actions to those of each component, riboflavin and nicotinic acid.

To ascertain this possibility, the present paper deals with vitamin $\mathrm{B}_{2}$ action, the fate of riboflavin part after the injection, and acute and chrcnic toxicity of this compound.

\section{EXPERIMENTAL}

\section{Materials}

FR was obtained from commercial source and used after it was purified with recrystallization. $\mathrm{B}_{2}-\mathrm{Nic}$ was prepared according to Kotaki and Yagi (5).

\section{Breeding Experiment}

Twenty-day-old male rats of Wistar strain (average body weight, 50 g) were used. The basal diet was essentially the same as that described by Forker and Morgan (6). See also (7).

The mixture of vitamin B supplements (daily dose per rat) was composed of thiamine $5 \mu \mathrm{g}$, pyridoxine $5 \mu \mathrm{g}$, folic acid $5 \mu \mathrm{g}$, pantothenic acid $25 \mu \mathrm{g}, p$-aminobenzoic acid $25 \mu \mathrm{g}$, myoinositol $625 \mu \mathrm{g}$ and choline chloride $1.25 \mathrm{mg}$. Besides these supplements, definite amount of $\mathrm{FR}$ or $\mathrm{B}_{2}$-Nic was added as shown in Table 1 . The mixture of fat soluble vitamins consisting of 10 I.U. of A, 1 I.U. of D and 0.1 mg of $\alpha$-tocopherol was separately prepared. They were administered compulsorily.

TABLE 1

Dose of FR or $B_{2}$-Nic

\begin{tabular}{ccc}
\hline \hline $\begin{array}{c}\text { Experimental } \\
\text { group }\end{array}$ & Dose of FR & Dose of $\mathrm{B}_{2}$-Nic \\
& $\mu g /$ day/rat & $\mu \mathrm{g} /$ day $/$ rat \\
$\mathrm{A}$ & 10 & 0 \\
$\mathrm{~B}$ & 0 & $10^{a}$ \\
$\mathrm{C}$ & 0 & $30^{a}$ \\
$\mathrm{D}_{0}$ & 0 & 0 \\
$\mathrm{D}_{1}{ }^{a}$ & 10 & 0 \\
$\mathrm{D}_{2}{ }^{b}$ & 0 & $10^{a}$ \\
$\mathrm{D}_{3}{ }^{a}$ & 0 & $30^{a}$ \\
\hline
\end{tabular}

a With respect to $\mathrm{FR}$.

$b$ Rats fed on riboflavin-deficient diet for 26 days were cured with FR or $\mathrm{B}_{2}$-Nic in amounts indicated. 
Rats were housed in each individual cage, and devided into four groups, A (standard group; administered with $10 \mu \mathrm{g}$ FR), B (administered with $\mathrm{B}_{2}$-Nic, $10 \mu \mathrm{g}$ with respect to $\mathrm{FR}$ ), $\mathrm{C}$ (administered with $\mathrm{B}_{2}-\mathrm{Nic}, 30 \mu \mathrm{g}$ with respect to $\mathrm{FR}$ ) and $\mathrm{D}$ (riboflavin deficient group) (see Table 1). To examine the curing effect of $\mathrm{B}_{2}$ Nic, group $\mathrm{D}$ was further divided into four groups, $\mathrm{D}_{0}$ (continuously administered with riboflavin-deficient diet), $\mathrm{D}_{1}$ (cured with $10 \mu \mathrm{g}$ FR), $\mathrm{D}_{2}$ (cured with $\mathrm{B}_{2}$-Nic, 10 $\mu \mathrm{g}$ with respect to $\mathrm{FR}$ ) and $\mathrm{D}_{3}$ (cured with $\mathrm{B}_{2}-\mathrm{Nic}, 30 \mu \mathrm{g}$ with respect to $\mathrm{FR}$ ) after the development of ariboflavinosis was completed. Each experimental group consisted of 10 animals. Experiments were performed in a room maintained at $23^{\circ}$ and at $55 \pm 5 \%$ of humidity. The growth rate of animals was recorded by weighing the body weight every noon. After breeding the animals for a desired period (e.g., 50 days in the main experiment), they were killed by decapitation under ether anesthesia and the liver and the kidney were rapidly removed. The total riboflavin content of these organs were measured fluorimetrically according to Yagi (8).

\section{Measurements of Flavin Concentration of Blood}

As test animals, male rabbits (ca. $1 \mathrm{~kg}$ of body weight) and male rats of Wistar strain (130-150 g of body weight) were used.

In one experiment, rabbits were injected intramuscularly with the aqueous solution of $\mathrm{FR}$ or $\mathrm{B}_{2}-\mathrm{Nic}$ in amount of $5 \mathrm{mg} / \mathrm{kg}$ body weight, with respect to riboflavin. Blood was collected from ear vein at definite intervals.

In another experiment, rats were injected intraperitoneally with $\mathrm{FR}$ or $\mathrm{B}_{2}$-Nic ( $1 \mathrm{mg} / \mathrm{rat}$, with respect to FR). Blood was collected at definite times after injection, by decapitation of rats under ether anesthesia.

Riboflavin content in blood was determined according to Yagi et al. (9).

\section{Measurements of the Rate of Excretion of Riboflavin into Urine}

Animals used were male rabbits (ca. $1 \mathrm{~kg}$ of body weight) and male rats of Wistar strain weighing about $100 \mathrm{~g}$.

In one experiment, rabbit equipped with catheter was fixed on its back and injected intramuscularly with $\mathrm{FR}$ or $\mathrm{B}_{2}$ - Nic in amount of $5 \mathrm{mg} / \mathrm{kg}$ body weight, with respect to FR. Urine was collected by the aid of catheter.

In another experiment, 24 hour urine was collected from rat injected intraperitoneally with $\mathrm{FR}$ or $\mathrm{B}_{2}-\mathrm{Nic}$ in amount of $2 \mathrm{mg} / \mathrm{rat}$, with respect to FR. Riboflavin derivatives excreted in urine were analyzed by paper chromatography using $n$-butanol-acetic acid-water $(4: 1: 2, \mathrm{v} / \mathrm{v} / \mathrm{v})$ as a developer. Flavin content in urine was measured according to Yagi (8).

\section{Acute Toxicity Test}

The acute toxicity test of $\mathrm{B}_{2}-\mathrm{Nic}$ was made using male rats (about $100 \mathrm{~g}$ in body weight) of Wistar strain and male mice (dd homogeneous strain, about $20 \mathrm{~g}$ in body weight). One experimental group consisted of 10 animals.

$\mathrm{B}_{2}$-Nic dissolved in diluted $\mathrm{HCl}$ was compulsorily administered per os.

\section{Chronic Toxicity Test}

Chronic toxicity test of $\mathrm{B}_{2}-\mathrm{Nic}$ was made using young male rats (about 25 days old) of Wistar strain. 
Histological Investigation of Organs and Tissues

Heart control

Lung control

Liver control
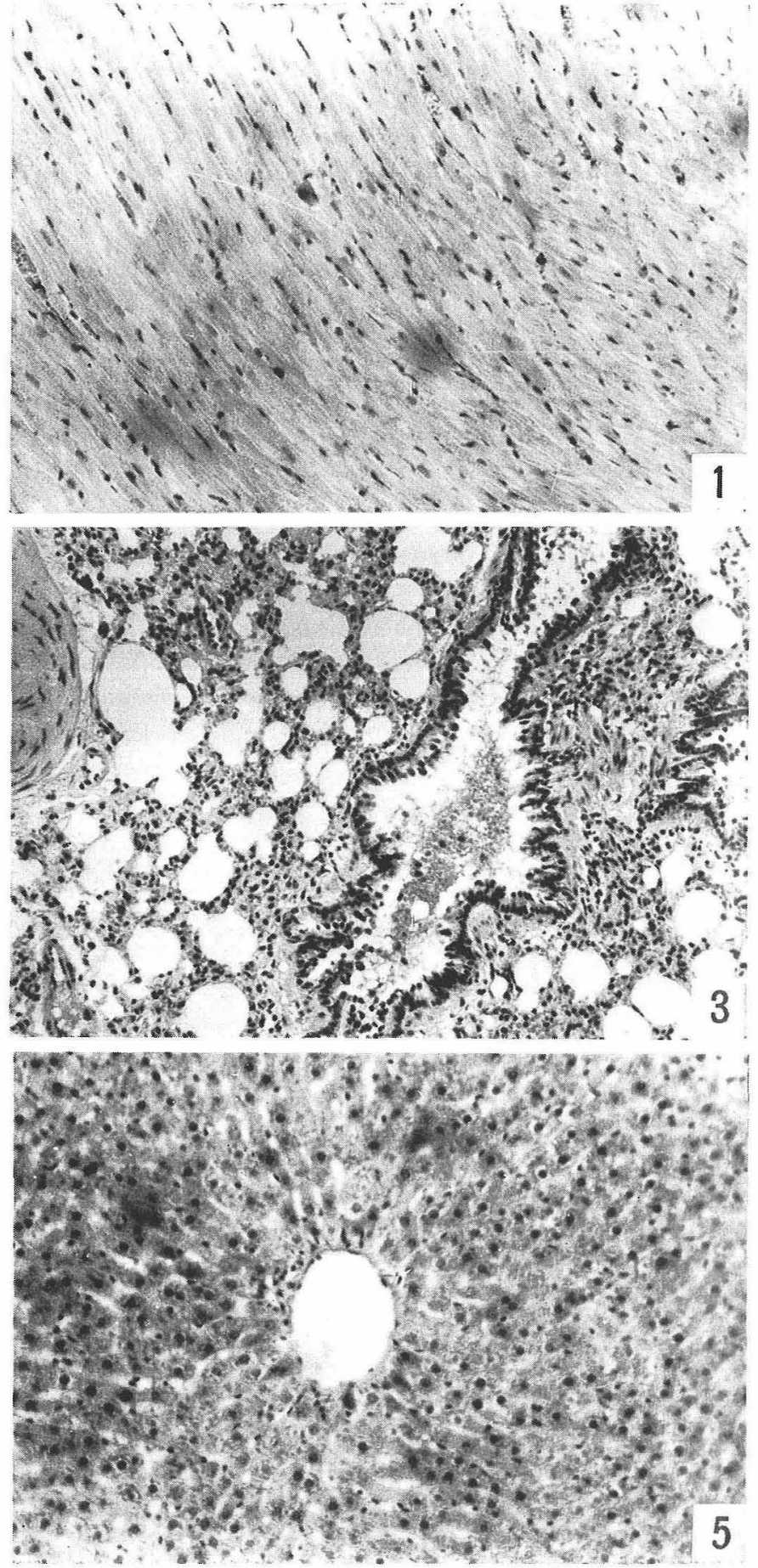


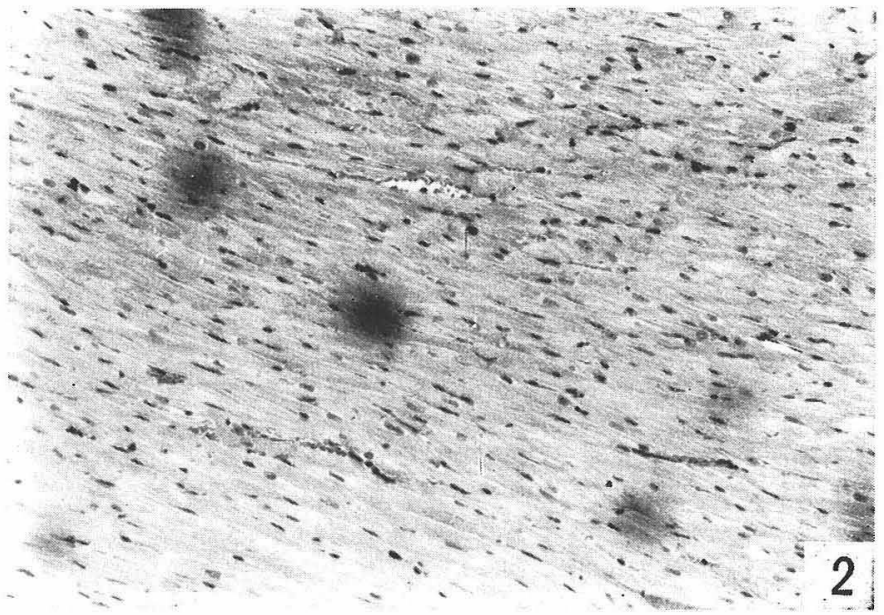

Heart administered with $\mathrm{B}_{2}-\mathrm{Nic}$

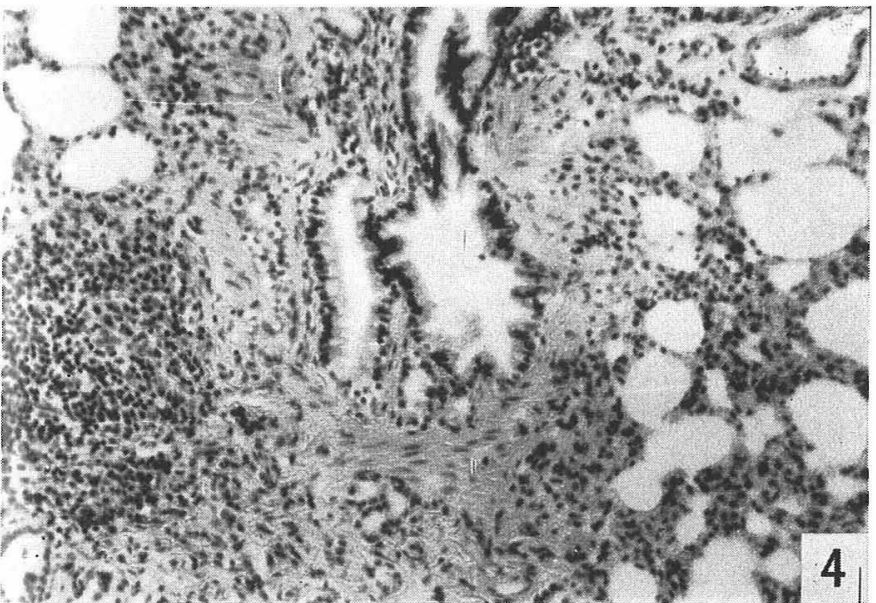

Lung administered with H. $\mathrm{B}_{2}-\mathrm{Nic}$

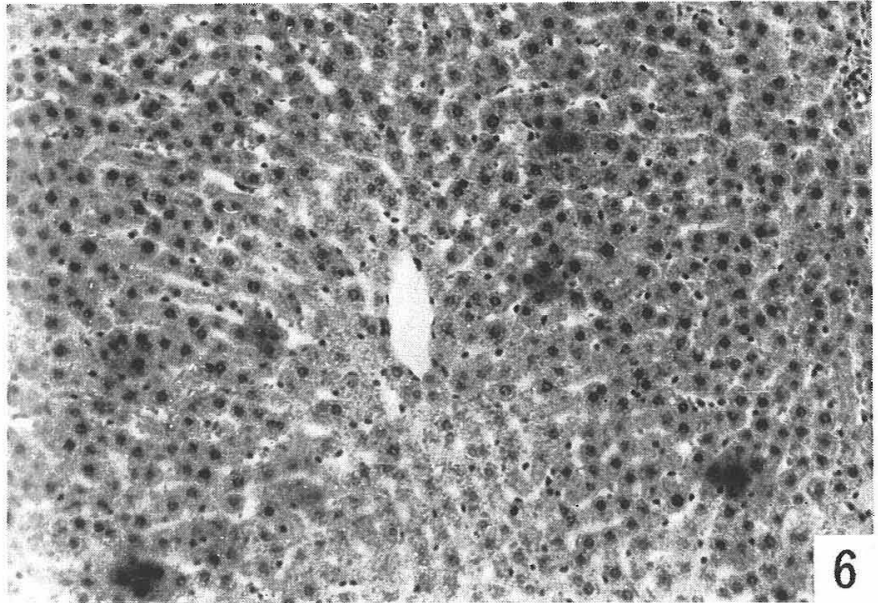

Liver administered with $\mathrm{B}_{2}-\mathrm{Nic}$ 
Kidney control

Spleen control

Stomach control

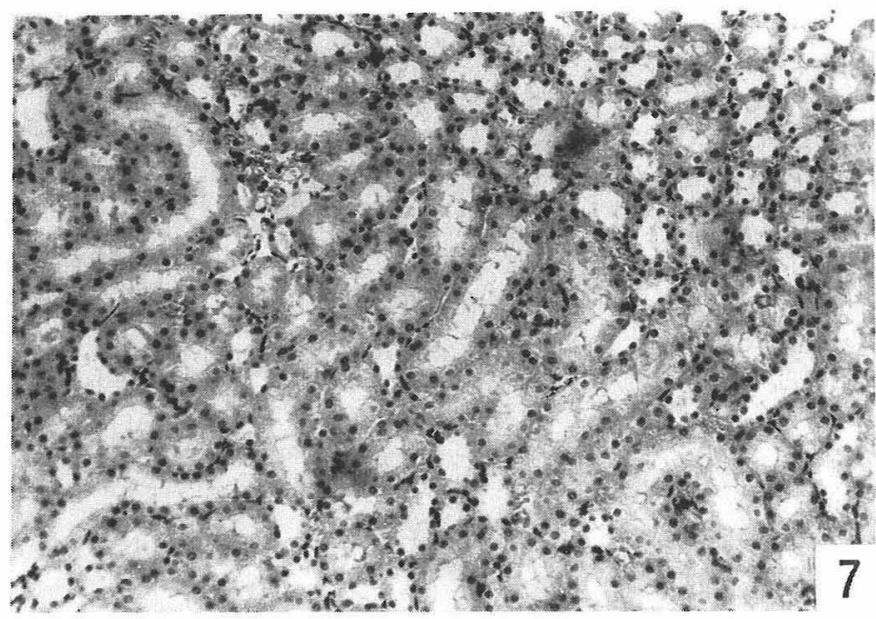

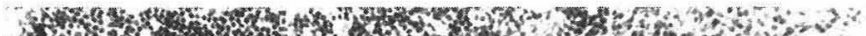
4.

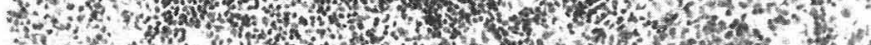

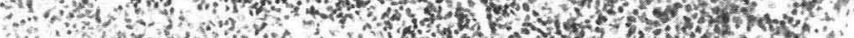

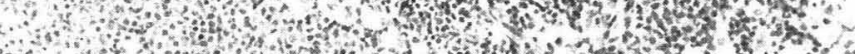
nom on

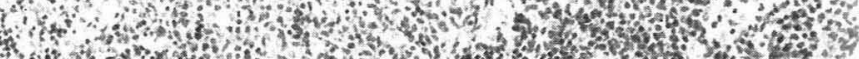
a

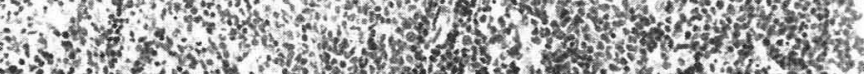

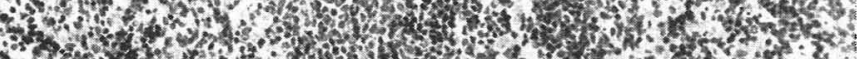

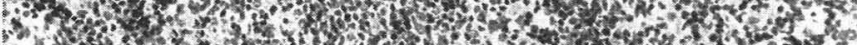

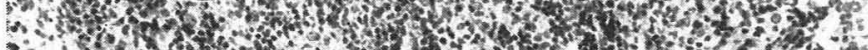

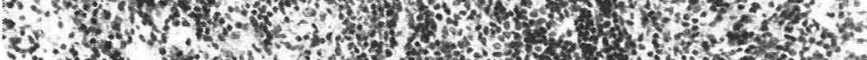

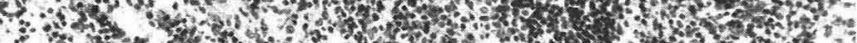

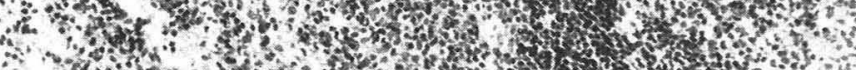

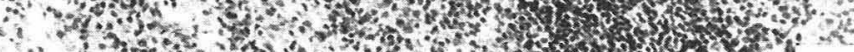
4.

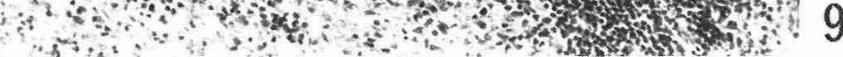

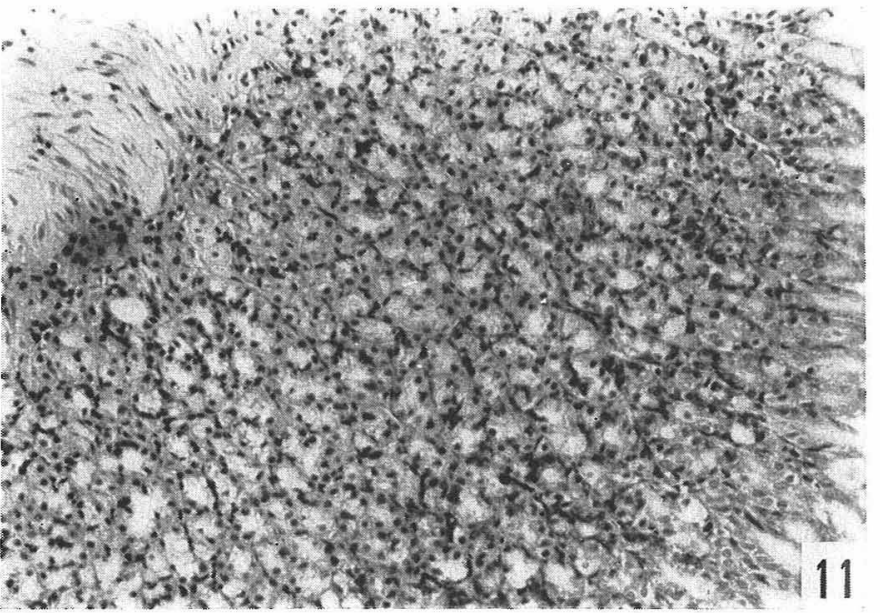




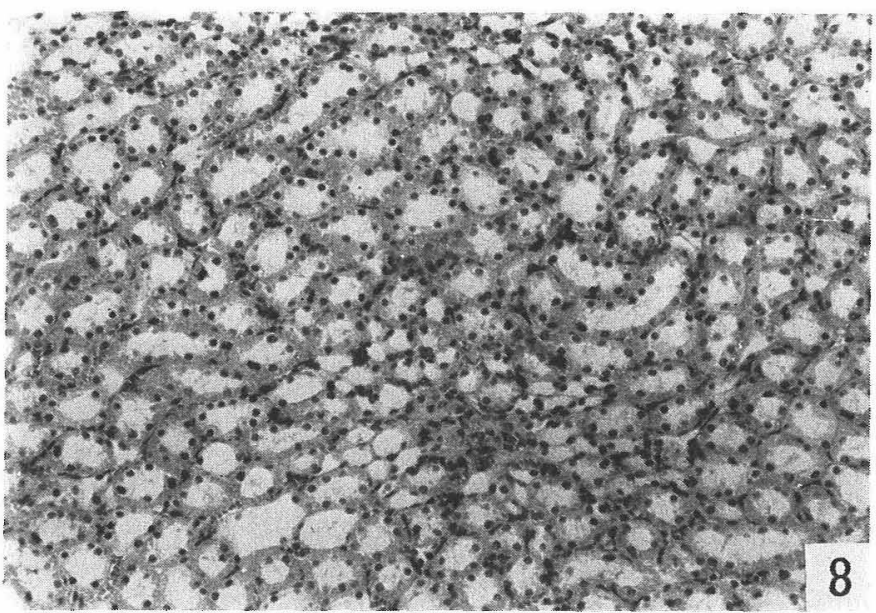

Kidney administered with $\mathrm{B}_{2}$-Nic

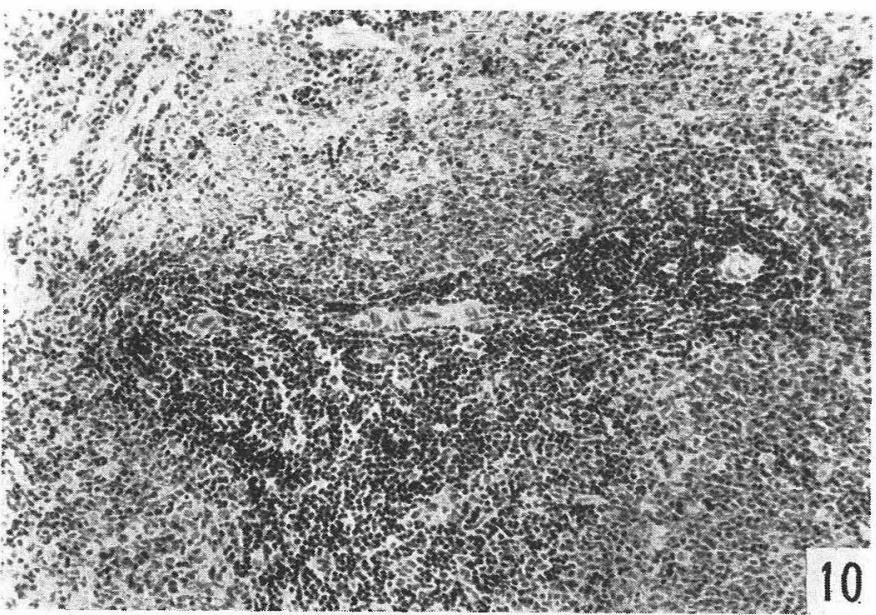

Spleen administered with $\mathrm{B}_{2}-\mathrm{Nic}$

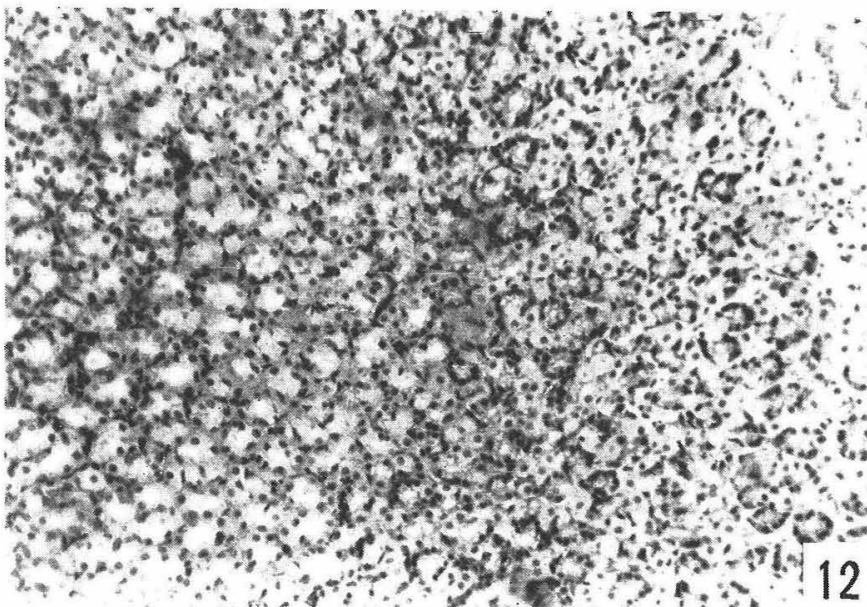

Stomach administered with $\mathrm{B}_{2}$-Nic 
Intestine control

Testis control
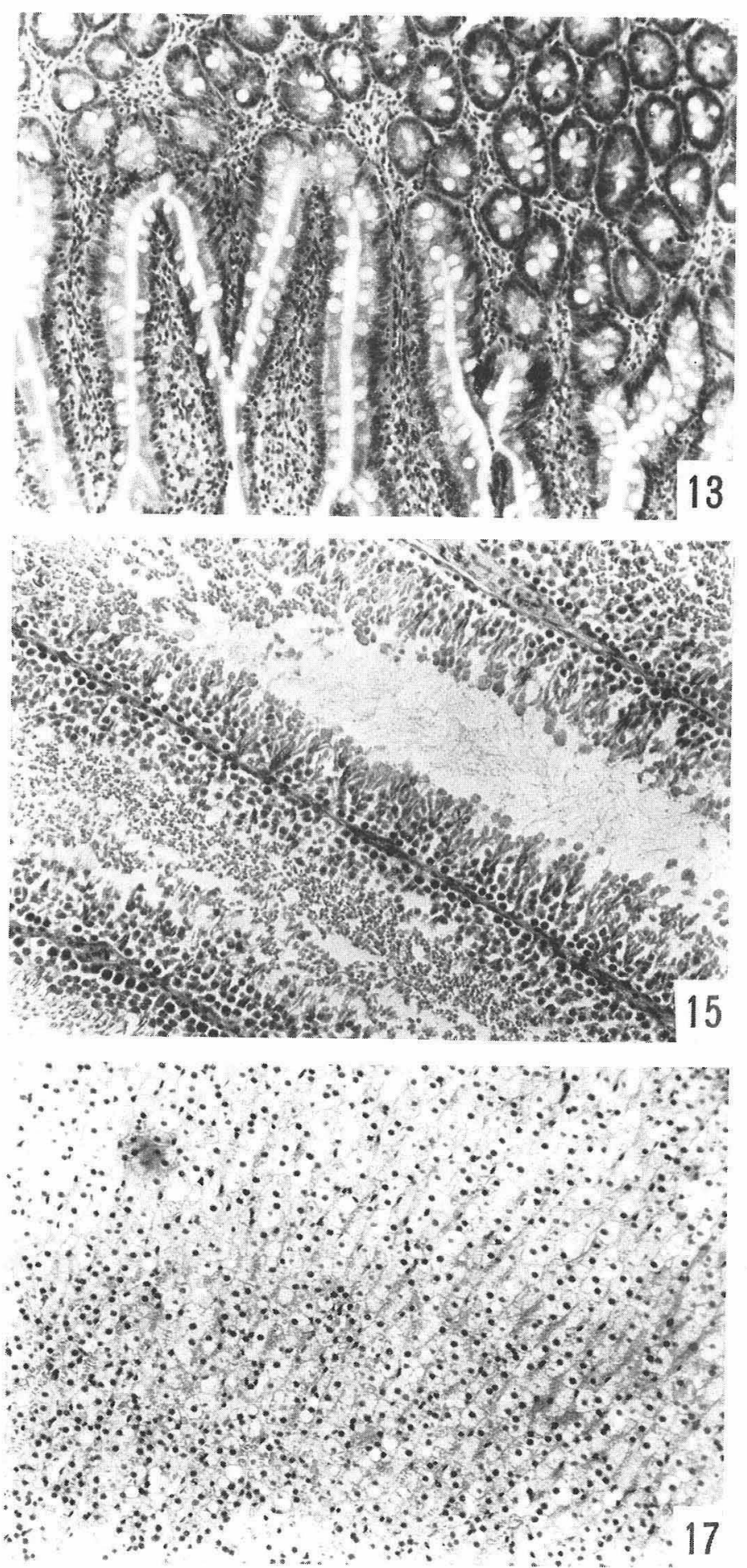

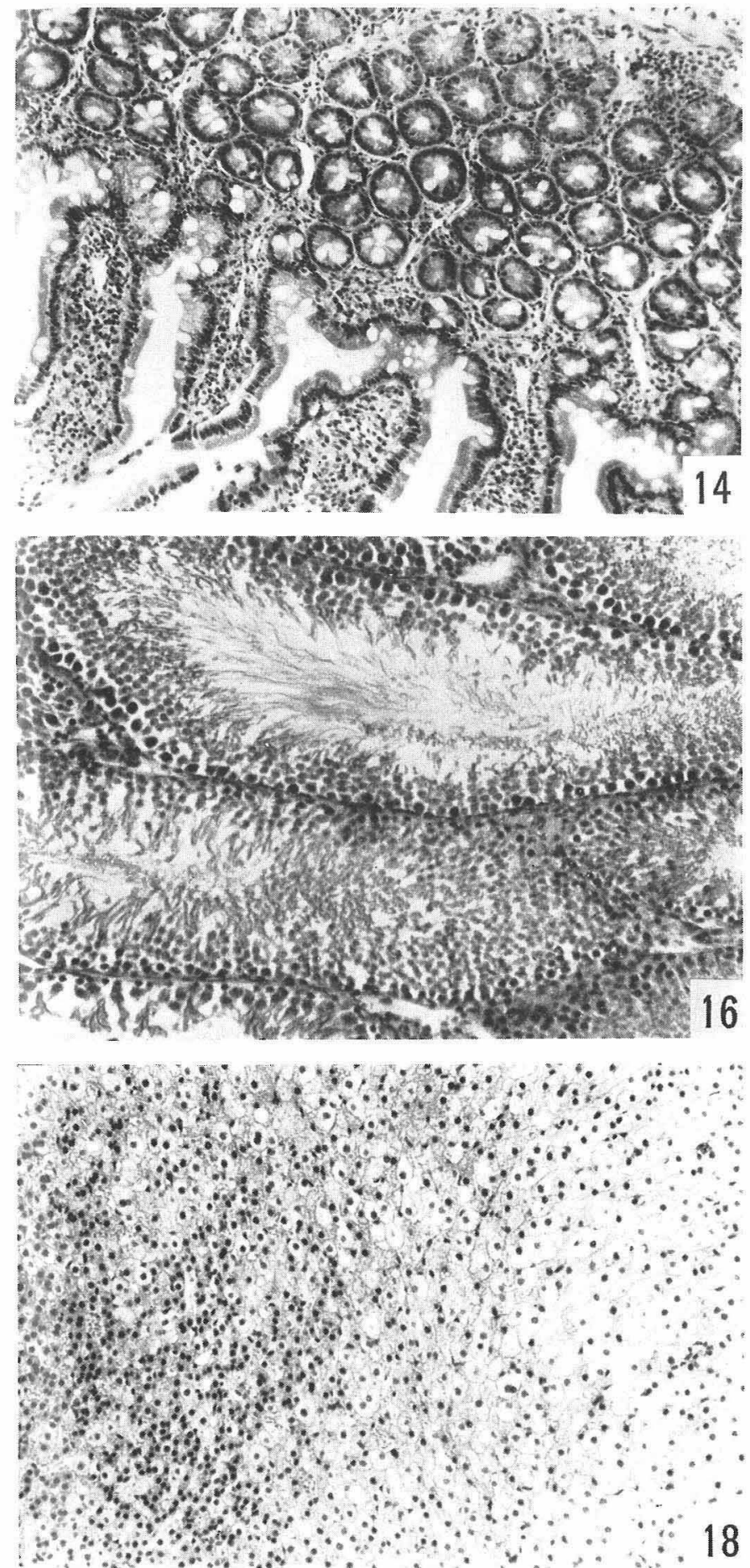

Intestine administered with $\mathrm{B}_{2}$-Nic with $\mathrm{B}_{2}$-Nic

Adrenal gland

administered with $\mathrm{B}_{2}-\mathrm{Nic}$ 


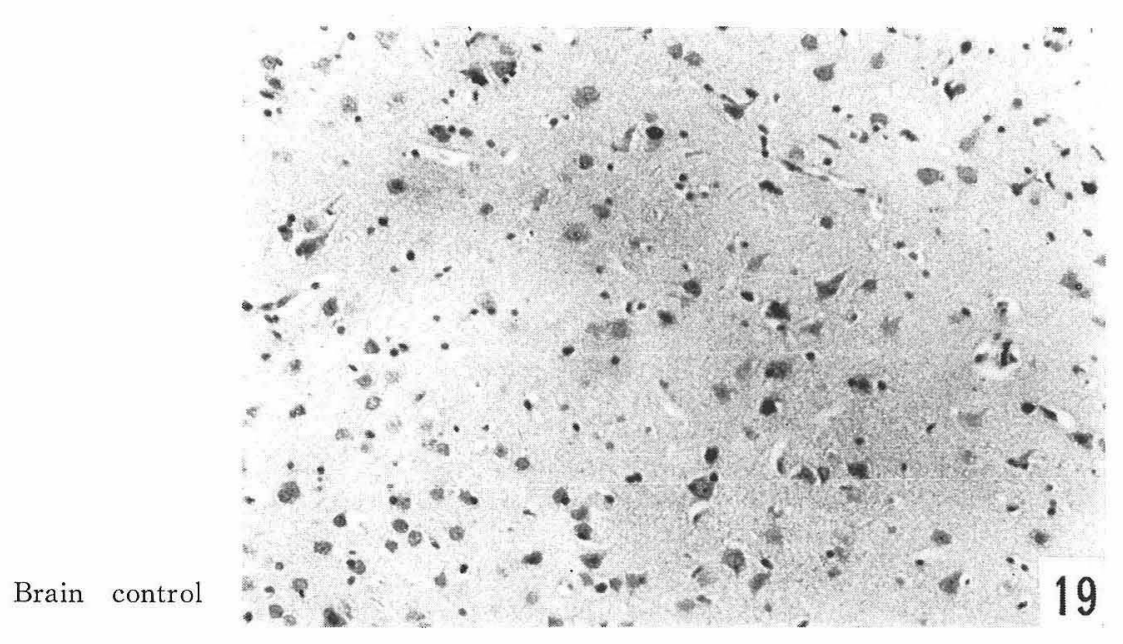

In our convenience of administrating $\mathrm{B}_{2}$-Nic orally, a sort of cream composed of $\mathrm{B}_{2}$-Nic $(20 \mathrm{~g})$, sucrose $(30 \mathrm{~g})$, shortening $(30 \mathrm{~g})$ and a small amount of water was prepared. Such a device made it possible to administer the desired amount of $B_{2^{-}}$ Nic accurately and easily. Each rat was administered compulsorily with $230 \mathrm{mg} /$ day $/ \mathrm{kg}$ body weight of this compound. Rats of experimental (administered with $\mathrm{B}_{2}-\mathrm{Nic}$ ) and control (no addition) groups were housed in each individual cage and all fed on CLEA (CE-2) diet obtained from Nippon Haigō Shiryō Co., in a room maintained at $23^{\circ}$ and at $55 \pm 5 \%$ of humidity, throughout this test.

The body weight gain of animals tested were measured every week. After 6 months' feeding, the measurements of the weight of each organ, hematological examination on blood, and histological investigation of organs and tissues were made.

\section{Results}

\section{Vitamin $B_{2}$ Action of $B_{2}-N i c$}

Effect of $B_{2}$-Nic on the Growth of Young Rats - The growth rate of each experimental group (A-D) is shown in Fig. 1. The riboflavin-deficient group (D) showed no significant growth, and fell into ariboflavinosis after 26 days of breeding. The symptom of ariboflavinosis observed was the same as previously described (10).

At this stage, the total flavin concentration of the liver and kidney was found to be remarkably decreased (see below). However, group B (administered with $\mathrm{B}_{2}-\mathrm{Nic}$ in amount of $10 \mu \mathrm{g}$ with respect to $\mathrm{FR}$ ) showed no symptom of deficiency during 50 days of breeding; in fact it showed considerable growth, though fairly slower than that of group A. Group C (administered with $\mathrm{B}_{2}-\mathrm{Nic}$ in amount of 30 $\mu \mathrm{g}$ with respect to FR) showed better growth than that of group B. No symptom of riboflavin deficiency was also found in this case. No death was found in groups $\mathrm{A}, \mathrm{B}$, and $\mathrm{C}$ during 50 days of breeding, in contrast to high mortality of group D (Six out of 10 animals died during the experiment).

Ariboflavinosis-Curing Effect of $\mathrm{B}_{2}$-Nic - As shown in Fig. 2, curing effect 


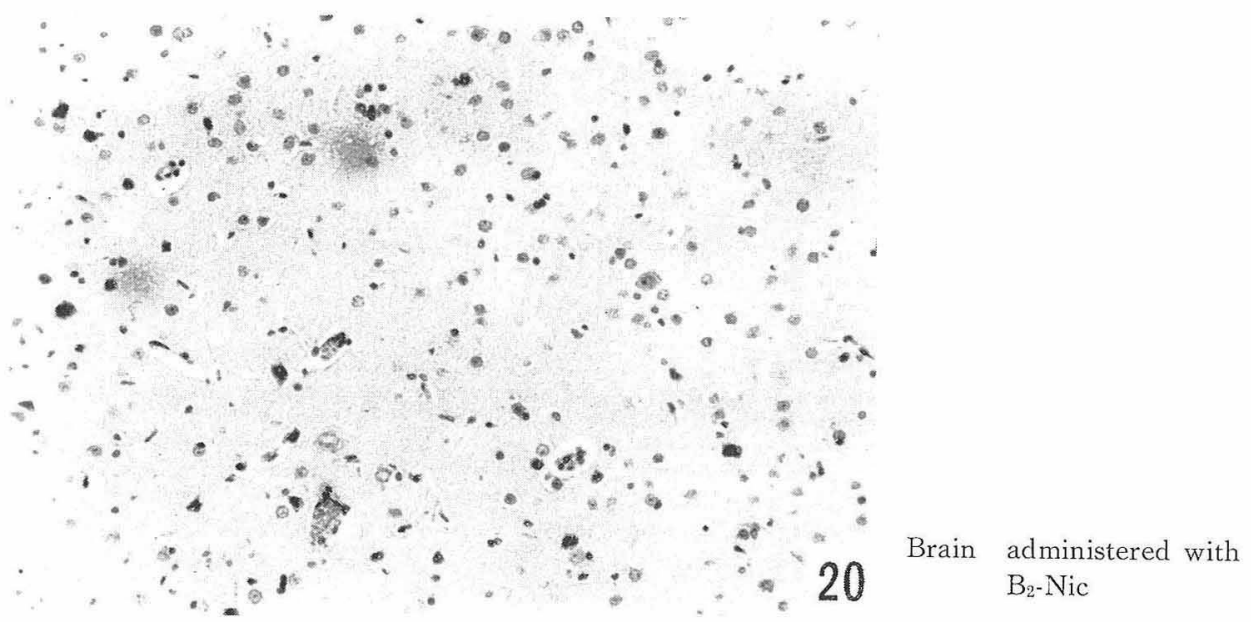

of FR on ariboflavinosis is noticeable. Stunted rats can be also cured by administering $\mathrm{B}_{2-\mathrm{Nic}}$ as shown in Fig. 2, but its effect was found to be somewhat inferior to that of FR.

Hepatic and Renal Flavin Levels of Rats Administered with $B_{2}$-Nic- Analytical data on the hepatic and renal flavin level of each experimental group

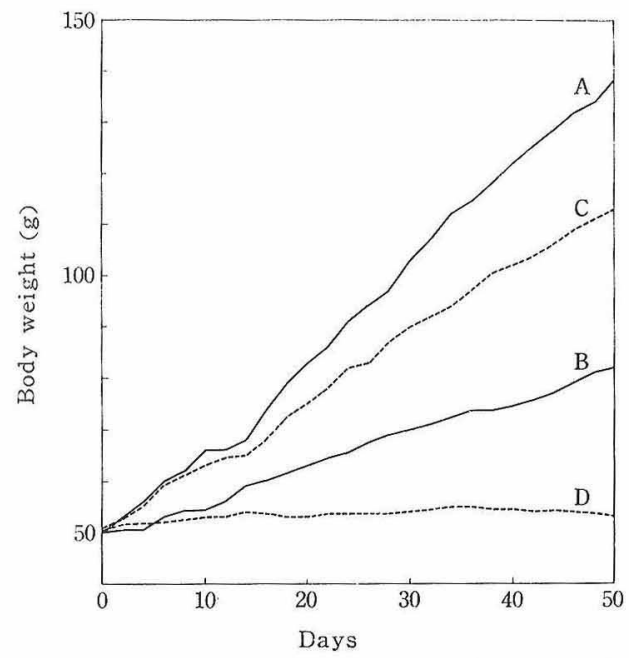

FIG. 1 Effect of $B_{2}$-Nic on the Growth of Albino Rats

A, group administered with $10 \mu \mathrm{g} /$ day/rat of FR; B, group administered with $10 \mu \mathrm{g} /$ day/rat of $\mathrm{B}_{2}$-Nic (with respect to FR); $\mathrm{C}$, group administered with $30 \mu \mathrm{g} / \mathrm{day} / \mathrm{rat}$ of $\mathrm{B}_{2}$-Nic (with respect to FR); D, riboflavin-deficient group (six out of ten animals died during the experiment. Body weight shown is the average of survived animals).

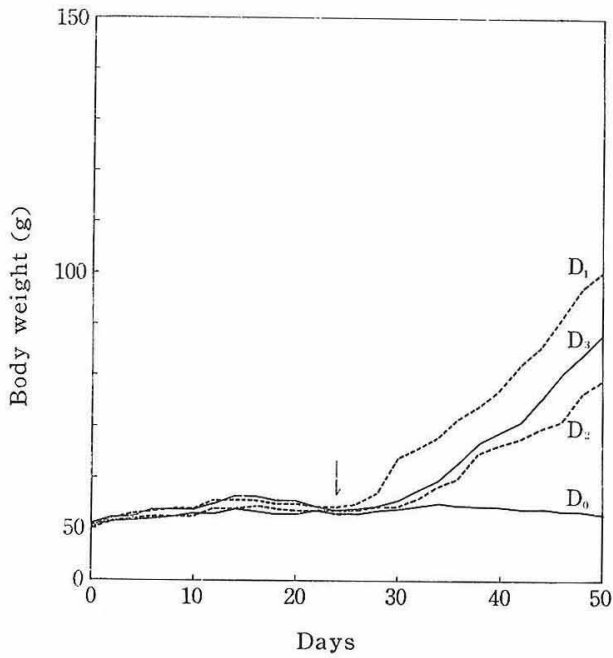

FIG. 2 Curing Effect of $\mathrm{B}_{2}$-Nic on Rats Suffering from Ariboflavinosis

$\mathrm{D}_{0}$, no addition; $\mathrm{D}_{1}$, group cured with $10 \mu \mathrm{g} /$ day/rat of $\mathrm{FR} ; \mathrm{D}_{2}$, group cured with $10 \mu \mathrm{g} /$ day/rat of $\mathrm{B}_{2}-\mathrm{Nic}$ (with respect to $\mathrm{FR}$ ); $\mathrm{D}_{3}$, group cured with $30 \mu \mathrm{g} / \mathrm{day} / \mathrm{rat}$ of $\mathrm{B}_{2}-\mathrm{Nic}$ (with respect to FR).

The arrow indicates the day when the curing experiments were initiated. 
TABLE 2

Hepatic and Renal Flavin Concentrations of Experimental Groups

\begin{tabular}{|c|c|c|c|}
\hline \multirow{2}{*}{\multicolumn{2}{|c|}{ Experimental group }} & \multicolumn{2}{|c|}{ Flavin concentration $a$} \\
\hline & & Liver & Kidney \\
\hline & & \multicolumn{2}{|c|}{$\mu g / g$ wet tissue } \\
\hline A & (administered with $10 \mu \mathrm{g} / \mathrm{day} / \mathrm{rat}$ of $\mathrm{FR}$ ) & 29.6 & 32.1 \\
\hline & $\left(\text { administered with } 10 \mu \mathrm{g} / \text { day/rat of } \mathrm{B}_{2}-\mathrm{Nic}\right)^{b}$ & 17.2 & $\begin{array}{l}32.1 \\
27.5\end{array}$ \\
\hline & $\left(\text { administered with } 30 \mu \mathrm{g} / \mathrm{day} / \mathrm{rat} \text { of } \mathrm{B}_{2}-\mathrm{Nic}\right)^{b}$ & 20.5 & 28.5 \\
\hline & (no addition) & 12.7 & 22.5 \\
\hline $\mathrm{D}_{1} c$ & (cared with $10 \mu \mathrm{g} / \mathrm{day} / \mathrm{rat}$ of $\mathrm{FR}$ ) & 24.5 & 30.8 \\
\hline & $=\left(\text { cured with } 10 \mu \mathrm{g} / \text { day } / \text { rat of } \mathrm{B}_{2}-\mathrm{Nic}\right)^{b}$ & 16.7 & 28.3 \\
\hline $\mathrm{D}_{3} c$ & (cured with $30 \mu \mathrm{g} /$ day $/$ rat of $\left.\mathrm{B}_{2}-\mathrm{Nic}\right)^{b}$ & 17.9 & 25.0 \\
\hline
\end{tabular}

$a$ Average of 10 animals. $b$ With respect to FR.

$c$ Cured after being stunted for 26 days.

after 50 days of breeding are listed in Table 2. Flavin levels of group A were in good accord with those determined previously for normal rats (11).

Flavin levels of rats administered with $\mathrm{B}_{2}$-Nic (group $\mathrm{B}$ and $\mathrm{C}$ ) were found to be somewhat lower than those of group A. However, the decrease in such extents of flavin level in these organs is unlikely to give rise to ariboflavincsis.

In the case of group $\mathrm{D}$, maximal decrease in flavin level was attained during the initial 25 days of the breeding experiment, and further significant decrease was not found during the following 25 days. However, when stunted rats were cured with $\mathrm{FR}$ or $\mathrm{B}_{2}$-Nic, flavin levels of these organs obviously increased. In good agreement with the curing experiments mentioned above, however, the rates of increase in flavin level of these organs of rats administered wth $\mathrm{B}_{2}$ $\mathrm{Nic}$ (group $\mathrm{D}_{2}$ and $\mathrm{D}_{3}$ ) were lower than those of rats administered with FR (group $\mathrm{D}_{1}$ ).

2. Changes in Flavin Concentrations in Blood and in Urine after the Administration of $\mathrm{B}_{2}$-Nic

Charging Experiments of $\mathrm{B}_{2}-\mathrm{NiC}$ on Rabbits - Fig. 3A shows the rate of excretion of flavin into urine of rabbit injected intramuscularly with 5 $\mathrm{mg}$ of FR. In this case, the excretion was considerably rapid; the amount of FR appeared in urine within 5 hours after injection corresponds to

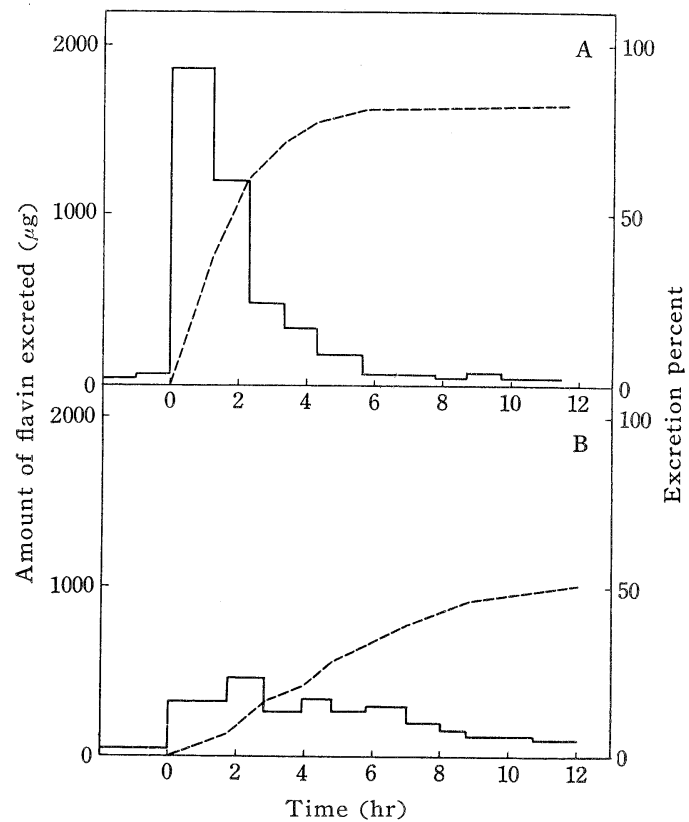

FIG. 3 Time Courses of the Excretion of Flavin into Urine of Rabbits Administered Intramuscularly with $\mathrm{FR}$ or $\mathrm{B}_{2}-\mathrm{Nic}$

$\mathrm{A}$, administered with $5 \mathrm{mg}$ of $\mathrm{FR}$; $\mathrm{B}$, administered with $5 \mathrm{mg}$ of $\mathrm{B}_{2}-\mathrm{Nic}$ (with respect to FR) Solid line indicates the amount of flavin excreted, and broken line demonstrates the percentage of the amount of flavin excreted versus its dose. 
TABLE 3

Change in Blood Flavin Concentration of Rabbits Administered with FR or $\mathrm{B}_{2}$-Nic

\begin{tabular}{ccc}
\hline \multirow{2}{*}{$\begin{array}{c}\text { Time after } \\
\text { injection }\end{array}$} & \multicolumn{2}{c}{ Blood flavin concentration } \\
\cline { 2 - 3 } & $\begin{array}{c}\text { Administered } \\
\text { with FR }{ }^{a}\end{array}$ & $\begin{array}{c}\text { Administered } \\
\text { with B } \text { B }_{2} \text { Nic } a\end{array}$ \\
\hline$h r$ & & $\mu g / 100 \mathrm{ml}$ \\
0 & 4.8 & 5.2 \\
1 & 22.5 & 14.3 \\
5 & 7.8 & 9.8 \\
10 & 3.6 & 14.8 \\
20 & 4.7 & 6.8 \\
\hline
\end{tabular}

a Administered with $5 \mathrm{mg}$ of samples with respect to FR.

$60 \%$ of that of injected FR. The result is in good accord with that previously reported (3).

However, as indicated in Fig. 3B, when rabbit was injected with $5 \mathrm{mg}$ of $\mathrm{B}_{2}$ Nic (with respect to FR), the rate of excretion of flavins into urine considerably dropped. Even 10 hours after the injection, the amount of flavin excreted in urine was found to be as low as $50 \%$ of the injected amount. This fact strongly suggests that the riboflavin moiety of $\mathrm{B}_{2}-\mathrm{Nic}$ is more accumulative in living body than FR.

Changes in the concentration of flavin in blood of rabbits administered with FR or $\mathrm{B}_{2}$-Nic are shown in Table 3. The behavior of FR was of temporality; its blood concentration rapidly increased within an hour after injection, then rapidly decreased, and turned to almost the normal level at the time about 10 hours after injection.

In the case of $\mathrm{B}_{2}-\mathrm{Nic}$, the blood flavin concentration of the rabbit was gradually increased after the injection, and the maximal concentration, which was fairly lower than that of the rabbit injected with FR, was attained at the time about two hours after the injection. In this case, blood flavin concentration was found to be kept 2-3 times higher than the normal level for fairly a long time.

Charging Experiments of $B_{2}-N i c$ on Rats—The accumulative nature of the ribollavin moiety of $\mathrm{B}_{2}$-Nic was also observed in the experiments using albino rats as test animals. As indicated in Fig. 4, blood flavin concentration of rats injected with FR increased rapidly, and attained its maximum 1 hour after the injection, and then rapidly decreased to a normal level within the following 4 hours. This fact indicates that the temporal nature of the increase in blood flavin concentration upon FR injection is equally true for different species of animals.

On the other hand, the blood flavin concentration of rats injected with $\mathrm{B}_{2}-\mathrm{Nic}$ increased rather slowly, and gradually decreased after its maximum is attained two hours after the injection. The concentration is higher than normal level even 10 hours after the injection.

The results of experiments on excretion of flavin into urine of rats also indicated that $\mathrm{B}_{2}-\mathrm{Nic}$ is more accumulative in animal body than FR. As shown in Table 4 the amount of flavin excreted in the 24 hour urine of rats administered 


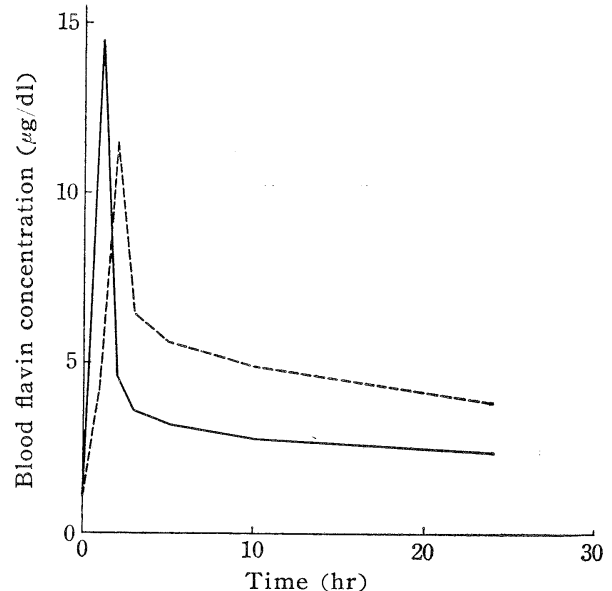

FIG. 4 Change in the Blood Flavin Con centration with Time of Rats Administered Intraperitoneally with $1 \mathrm{mg}$ of $F R$ or $B_{2}$. $N i c$ with respect to $F R$

Solid line indicates the change in the blood flavin concentration of rats administered with $\mathrm{FR}$, and broken line indicates the change in the blood flavin concentration of rat administered with $\mathrm{B}_{2}$-Nic. with FR reached $80 \%$ of the injected amount, whereas the amount excreted into the 24 hour urine when rats were injected with $\mathrm{B}_{2}$-Nic was only $40 \%$ of the injected amount in terms of FR.

Paper chromatographic analysis of flavin compounds in the 24 hour urine of rats administered with $\mathrm{B}_{2}$-Nic indicated that the main component excreted into urine is FR. However, as illustrated in Fig. 5, appearance of components of high $R f$ values in the $n$ butanol-acetic acid-water $(4: 1: 2, \mathrm{v} / \mathrm{v} / \mathrm{v})$ system was found. These spots fluoresce yellow, similarly to FR. Since such components were not found in 24 hour urine of rats administered with $\mathrm{FR}$, it may be possible to consider that $\mathrm{B}_{2}-\mathrm{Nic}$ and its partial hydrolysates can also be excreted into urine.

TABLE 4

The Amount of Flavin Excreted in the 24 Hour Urine of Rats Administered Intraperitoneally with $2 \mathrm{mg}$ of $F R$ or $B_{2}$-Nic (with respect to $F R$ )

\begin{tabular}{|c|c|c|}
\hline \multirow[b]{2}{*}{ Exp. No } & \multicolumn{2}{|c|}{ Amounts excreted $a$} \\
\hline & $\begin{array}{l}\text { Administered } \\
\text { with FR }\end{array}$ & $\begin{array}{l}\text { Administered } \\
\text { with } \mathrm{B}_{2}-\mathrm{Nic}\end{array}$ \\
\hline & \multicolumn{2}{|c|}{ per cent } \\
\hline 1 & 77.9 & 40.5 \\
\hline 2 & 82.7 & 41.9 \\
\hline
\end{tabular}

$a$ Per cent versus the dose.

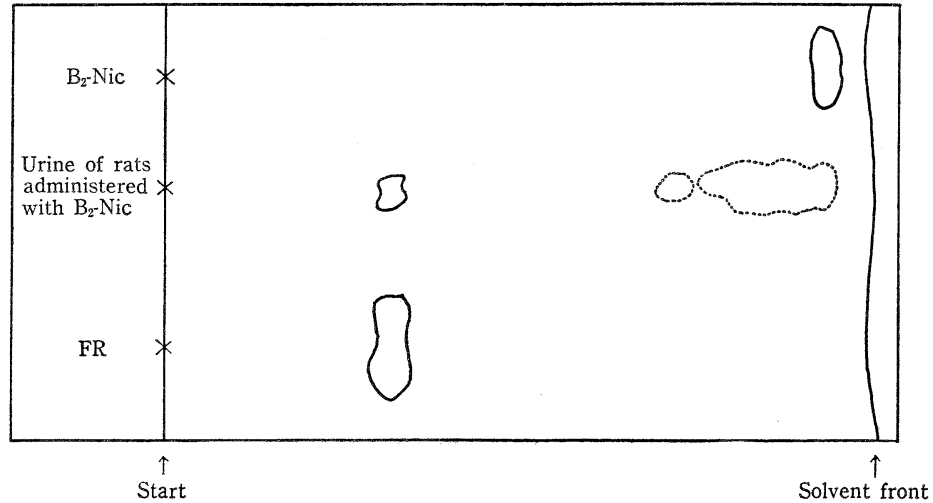

FIG. 5 Paper Chromatographic Patterns of Riboflavin and Its Derivatives Excreted in the 24 Hour Urine of Rats

Developer used: $n$-butanol-acetic acid-water $(4: 1: 2, \mathrm{v} / \mathrm{v} / \mathrm{v})$. 


\section{Acute and Chronic Toxicity Test}

Acute Toxicity Test The results of acute toxicity tests of $\mathrm{B}_{2}$-Nic were summarized in Table 5. No death was found even when rats were administered with $5.0 \mathrm{~g} / \mathrm{kg}$ body weight of $\mathrm{B}_{2}$-Nic. Since further addition was extremely difficult, it seems almost impossible to show $\mathrm{LD}_{50}$ value of this compound; it is considered to be harmless substance. No abnormality was found in appearance and in appetite, during the following 7 days after the administration.

TABLE 5

Mortality of Animals Administered with a Large Amount of $\mathrm{B}_{2}$-Nic

\begin{tabular}{cllc}
\hline \hline Exp. No. ${ }^{a}$ & Animals & Dose & Mortality \\
\hline & & $g / k g$ & per cent \\
1 & Rat & 0.15 & 0 \\
2 & Rat & 1.2 & 0 \\
3 & Rat & 5.0 & 0 \\
4 & Mouse & 0.5 & 0 \\
5 & Mouse & 1.0 & 0 \\
\hline
\end{tabular}

a In each experiment 10 animals were used.

Chronic Toxicity Test-As indicated in Fig. 6, no significant difference was found in the growth rates between animals administered with $230 \mathrm{mg} /$ day/ $\mathrm{kg}$ body weight of $\mathrm{B}_{2}$-Nic and control animals, during the 6 months, breeding. No death was found in this experimental period; no abnormality was observed in appearance, in appetite, and in behavior.

The hematological examination was made after 6 months, breeding, but no significant difference was found in the numbers of erythrocytes and leucocytes, and in the Sahli values between the animals tested and those of control.

Rats were then killed by decapitation under ether anesthesia and macroscopic examination of each organ was made. No change was found in organs attributable to the administration of $\mathrm{B}_{2}$ Nic. No significant difference was found in the average weight of organs and tissues of all the animals tested (see Table 6).

Furthermore, histological examination was made for all the animals used.

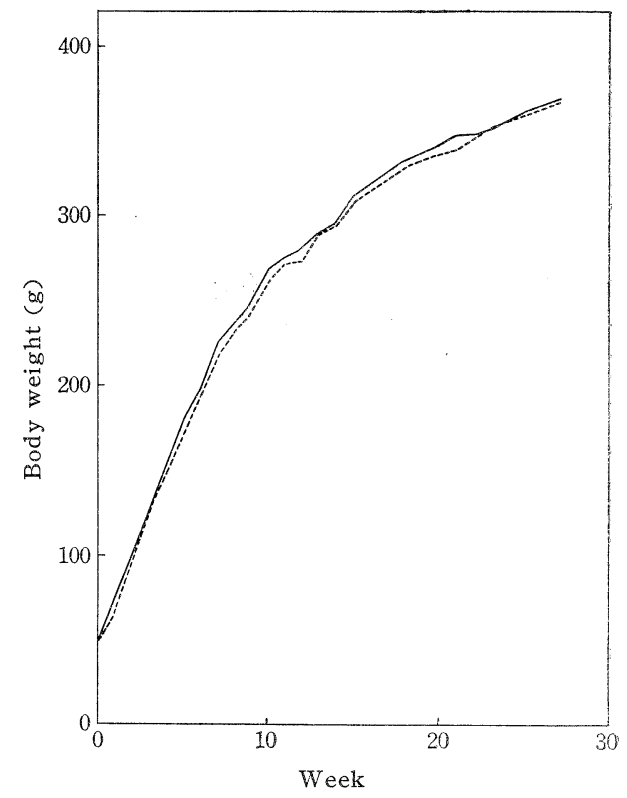

FIG. 6 Average Body Weight of Rats Fed on $230 \mathrm{mg} / \mathrm{day} / \mathrm{kg}$ Body Weight of $B_{2}-N i c$ and Those of Controls

Solid line: administered with $\mathrm{B}_{2}-\mathrm{Nic}$ Dotted line: controls. 
TABLE 6

Weights of Organs and Tissues of Rats Administered with $B_{2}$-Nic as Compared with Controls

\begin{tabular}{|c|c|c|}
\hline Organs or tissues & $\begin{array}{l}\text { Rats administered } \\
\text { with } \mathrm{B}_{2} \text {-Nic }\end{array}$ & Control \\
\hline $\begin{array}{l}\text { Liver }^{a} \\
\text { Heart } \\
\text { Brain }\end{array}$ & $\begin{array}{r}10.88 \pm 2.57 \\
1.05 \pm 0.25 \\
1.84 \pm 0.19\end{array}$ & $\begin{array}{r}10.29 \pm 3.31 \\
1.16 \pm 0.34 \\
1.97 \pm 0.07\end{array}$ \\
\hline Lung $^{a}\left\{\begin{array}{l}\text { left } \\
\text { right }\end{array}\right.$ & $\begin{array}{l}0.669 \pm 0.131 \\
0.931 \pm 0.231\end{array}$ & $\begin{array}{l}0.519 \pm 0.181 \\
0.921 \pm 0.271\end{array}$ \\
\hline Kidney ${ }^{a}\left\{\begin{array}{l}\text { left } \\
\text { right }\end{array}\right.$ & $\begin{array}{l}1.13 \pm 0.18 \\
1.14 \pm 0.14\end{array}$ & $\begin{array}{l}1.11 \pm 0.34 \\
1.12 \pm 0.42\end{array}$ \\
\hline Testis $a\left\{\begin{array}{l}\text { left } \\
\text { right }\end{array}\right.$ & $\begin{array}{l}1.43 \pm 0.37 \\
1.41 \pm 0.29\end{array}$ & $\begin{array}{l}1.47 \pm 0.13 \\
1.49 \pm 0.21\end{array}$ \\
\hline Spleen ${ }^{a}$ & $0.787 \pm 0.200$ & $0.937 \pm 0.58$ \\
\hline Adrenal gland $b$ & $42.84 \pm 8.61$ & $44.35 \pm 8.70$ \\
\hline
\end{tabular}

$a$ Wet weight $(\mathrm{g}) . \quad b$ Wet weight $(\mathrm{mg})$.

However, as shown by photograph 1-20, noticeable pathological change was not observed in all the rats tested, and no significant difference was found between the rats administered with $\mathrm{B}_{2}-\mathrm{Nic}$ and controls. It was concluded that no histological change attributable to the administration of $\mathrm{B}_{2}-\mathrm{Nic}$ was observed.

\section{Discussion}

The results of the present study have indicated that the administration of $B_{2}$ $\mathrm{Nic}$ to riboflavin-deficient animals prevents the development of ariboflavinosis. In addition, it showed a curing effect on rats suffering from ariboflavinosis. Although its vitamin effect was found to be somewhat lower than FR, the fact that its vitamin effect increases with the increase in the amount of administration indicates that this compound does not act competitively with FR. In support of this view, it was confirmed that this substance has no chronic toxicity on rats, at least up to the dose of $230 \mathrm{mg} / \mathrm{day} / \mathrm{kg}$ body weight.

To act as vitamin in the living body, it would be necessary for $\mathrm{B}_{2}$-Nic that all of the four nicotinic acids are liberated. If this assumption be valid, it must be considered that $\mathrm{B}_{2}$-Nic can be hydrolyzed in the animal body to each component, FR and nicotinic acid, because the present result in fact indicated the vitamin action of $\mathrm{B}_{2}-\mathrm{Nic}$.

The accumulative nature of $\mathrm{B}_{2}-\mathrm{Nic}$ in the animal body was indicated in the present study. Nevertheless, the lower utilizability of $\mathrm{B}_{2}-\mathrm{Nic}$ as a vitamin in the animal body should be noted. This would be explained by assuming that the conversion $\mathrm{B}_{2}-\mathrm{Nic} \rightarrow \mathrm{FR}$ is a bottle-neck reaction for its utilization in the animal body. In support of this view, a part of injected $\mathrm{B}_{2}$-Nic was found to appear in the 24 hour urine of rat in tetra- or lower esters.

In view of the harmless nature of this compound as presently reported, its deposit-type nature in the animal body would be worth to consider. In fact, this derivative is somewhat inferior to FR in acting as vitamin, but it does not always 
spoil the usefulness of this compound in the field of medical science. Its accumulative nature in the animal body would be valuable as far as it is used for pharmacological purposes. In this connection, it is worth to note the decrease of the peroxide value of fat by riboflavin derivative (12).

To develop further the potential usefulness of this compound, it may be necessary to clarify the pharmacological behavior of the nicotinate moiety in the animal body. Studies on this problem are now under progress, and the results will be reported in a succeeding paper of this series.

\section{REFERENCES}

1. Yagi, K., Okuda, J., and Dmitrovskii, A. A., J. Biochem., 48, 621 (1960).

2. Badgett, C. O., and Woodward, C. F., J. Am. Chem. Soc., 69, 2907 (1947).

3. Yagi, K., Okuda, J., and Matsubara, T., J. Vitaminol., 10, 275 (1964).

4. Lindquist, T., Svenska Lakartidn., 55, 1 (1958).

5. Kotaki, A., and Yagi, K., J. Vitaminol., 14, 247 (1968).

6. Forker, B. R., and Morgan, A. F., J. Biol. Chem., 209, 303 (1954).

7. Yagi, K., Kotaki, A., and Yamamoto, Y., J. Vitaminol., 11, 14 (1965).

8. Yagi, K., J. Biochem. 43, 635 (1956).

9. Yagi, K., Kikuchi, S., and Kariya, T., Vitamins, 8, 450 (1955).

10. Yagi, K., Yamamoto, Y., and Kobayashi, M., Vitamins, 32, 240 (1965).

11. Yagi, K., Okuda, J., and Yamada, M., Vitamins, 24, 171 (1961).

12. Yagi, K., Yamamoto, Y., and Sakurai, T., Vitamins, 32, 154 (1965). 